\title{
WHO FCTC Article 14 enforcement in Albania: An urgent issue to tackle
}

\author{
Enkeleint A. Mechili', Charis Girvalaki², Aurela Saliaj', Filippos T. Filippidis³, Constantine I. Vardavas ${ }^{2,4}$
}

\begin{abstract}
Tobacco use is a major preventable risk factor for non-communicable diseases such as cardiovascular disease, cancer etc. Smoking prevalence in Albania is high. The country ratified the World Health Organization Framework Convention on Tobacco Control (WHO FCTC) in 2006 and has passed different bills and adopted strict tobacco control laws during the years. Despite this, there is a huge gap in primary healthcare (PHC) personnel education in this field. Additionally, tobacco treatment support facilities, such as free of charge telephone quit lines, tobacco treatment clinics in hospitals or in the community, are lacking or not well established. Training of healthcare professionals in evidence-based practices as well as the development of national guidelines on tobacco treatment, capacity building for tobacco treatment delivery, pharmacotherapy availability, public opinion awareness and promotion of smoking cessation practices are some of the measures Albanian policy makers should undertake.
\end{abstract}

\section{AFFILIATION \\ 1 Department of Healthcare, Faculty of Public Health, University of Vlora, Vlora, Albania \\ 2 Medical School, University of Crete, Heraklion, Greece \\ 3 Department of Primary Care and Public Health, School of \\ Public Health, Imperial College, London, United Kingdom 4 Institute of Public Health, American College of Greece, Athens, Greece}

\section{CORRESPONDENCE TO \\ Enkeleint A. Mechili. Department of Healthcare, Faculty of Public Health, University of Vlora, Vlora, Kosova Street, P. Box 9401, Vlora, Albania. Email: mechili@ univlora.edu.al}

\section{KEYWORDS}

Framework Convention on Tobacco Control, Albania, pharmacotherapy, behavioural counseling

Received: 24 October 2018 Revised: 18 December 2018 Accepted: 23 January 2019

\section{COMMENTARY}

Tobacco use is the leading cause of preventable morbidity and mortality worldwide and a major preventable risk factor for cardiovascular disease, cancer and other diseases ${ }^{1}$. In response to the above, the World Health Organization (WHO) recognises tobacco dependence as a disease ${ }^{1}$ that can benefit from treatment. Nicotine addiction is the key component that makes smoking cessation a struggle. Even tobacco users who are highly motivated to quit, have a very high relapse rate within the first year ${ }^{2}$. However, tobacco users who seek help from a healthcare professional are up to four times more likely to successfully quit than those unassisted ${ }^{2}$.

The most recently published data on the Albanian population reveal that daily smoking prevalence (any smoked tobacco) is high among men $(41.0 \%$ of the population aged $\geq 15$ years) and in women ( $5.6 \%$ of the female population aged above 15 years $)^{3}$. According to studies conducted in Albania ${ }^{4,5}$, there is 
an urgent need for stronger enforcement of tobacco control policies.

Countries like Albania that are facing fiscal constraints have been found to report low rates of smoking cessation advice ${ }^{6}$; only $37.3 \%$ of smokers who visited a doctor, received advice to quit ${ }^{4}$. Additionally, only $6.8 \%$ of the Albanian population are former smokers ${ }^{5}$. Given the importance of support and advice to quit by healthcare professionals ${ }^{7}$, these results confirm the huge gap in tobacco treatment delivery in the country.

Article 14 of the WHO Framework Convention on Tobacco Control (WHO FCTC), has called for the integration of tobacco dependence treatment into daily clinical practice ${ }^{8}$. Albania ratified WHO FCTC in $2006^{3}$ and implemented strict Tobacco Control laws in 2007, including the development of an anti-smoking task-force. Results did provide some indications that adopting stricter tobacco control laws for advertising and exposure to secondhand smoke was a positive step ${ }^{4}$; however, tobacco treatment policies did not receive equal attention. Tobacco treatment support facilities, such as free-ofcharge telephone quit lines, tobacco treatment clinics in hospitals or in the community, are not currently available except for some health clinics and primary healthcare facilities ${ }^{3}$. It is also worth mentioning that, even though Albania has launched an annual check-up program for the population over the age of 35 years, primary healthcare (PHC) personnel are not well trained on counselling and smoking cessation. Furthermore, Nicotine Replacement Therapies (NRTs) are not available in Albania. Although Albanian authorities report that Bupropion and Varenicline are legally sold in the country (as presented in the WHO report on the global tobacco epidemic $)^{3}$, they are not readily accessible.

Enforcement of WHO FCTC Article 14 is imperative to achieve a decline in current smokers' percentage by increasing long-term abstinence rates. Primary healthcare can spearhead this effort, as it has an operational advantage in overall health promotion, a key component of which is tobacco prevention and tobacco treatment delivery. Primary healthcare professionals have a framework to integrate tobacco dependence treatment into their daily clinical practice, which makes patient centred, compassionate and coordinated primary care the optimal environment for providing advice to quit smoking ${ }^{8}$.

Furthermore, given the high rates of cardiovascular and respiratory diseases in Albania $(3696 / 100000 \text { and 386/100000, respectively })^{9}$ where smoking is a crucial determinant of both diseases, tobacco treatment delivery could be of great benefit for patients' health. It is well documented that the combination of behavioural counselling and pharmacotherapy are important components of successful tobacco treatment ${ }^{10}$. Brief smoking cessation advice provided by a healthcare professional significantly increases patient motivation to quit and smoking abstinence rates $^{7}$ while minimum counselling (3-5 minutes) offered by a clinician increases long-term smoking abstinence ${ }^{7}$. The launch of the aforementioned annual check-up program is an excellent opportunity for healthcare professionals to advise and motivate their patients, who may not be ready to quit, to make a quit attempt. Provision of clear and person-centred counselling from healthcare personnel as part of primary healthcare daily services is effective and inexpensive ${ }^{8}$.

Pharmacotherapy, the second pillar of successful tobacco treatment, has been shown to be effective in healthcare settings and for smokers with various co-existing conditions ${ }^{10}$. A 2008 meta-analysis showed that most smoking cessation medications (nicotine patch, gum, lozenges, nasal spray, inhaler, and sustained-release bupropion) approximately doubled the odds of achieving abstinence ${ }^{10}$. Varenicline and the use of NRT combination (nicotine patch plus a short-term form of NRT, used for more than 14 weeks) were associated with the highest estimated abstinence rates of $33 \%$ and $37 \%$, respectively ${ }^{10}$. Finally, a second recent meta-analysis by the Cochrane Collaboration found that the combination NRT (oral and patch) and varenicline provide similar benefits regarding efficacy, and both outperform monotherapy with NRT or bupropion $^{11}$. A combination of behavioural support and pharmacotherapy can increase abstinence rates fourfold ${ }^{10}$.

The argument for better provision of tobacco treatment is underpinned by the overwhelming evidence linking smoking cessation to health and economic benefits ${ }^{12}$. Research has shown that the 
excess risk of smoking-related coronary heart disease is reduced by approximately $50 \%$ within one year following smoking cessation, and to normal levels within five years ${ }^{13}$. As for cost-effectiveness, the cost per life-year saved is estimated to be from $€ 1500$ and to $€ 3000^{14}$.

In addition, there are several studies from countries that launched strategies for enforcing tobacco treatment delivery proving their effectiveness. A recent meta-analysis that included twenty-four randomized controlled trials, highlighted the efficacy of smoking cessation interventions in low- and middle-income countries (LMICs). The results revealed that NRTs, behavioral counseling and brief advice appear to be effective in aiding smoking cessation in LMICs ${ }^{15}$. Furthermore, a study using estimates of effectiveness and reach for 'return on investment' modelling of smoking cessation interventions with data from England showed that tobacco control policies such as tax increases and indoor smoking bans along with smoking cessation services (brief advice and use of NRT) can all increase quit attempt rates while quit success rates can be increased by provision of NRT, varenicline, bupropion, nortriptyline, cytisine and behavioural support ${ }^{16}$.

All the above highlight that Albanian authorities, synergistically with other tobacco control policies, need to prioritise the delivery of evidence-based tobacco treatment interventions combining behavioural counselling and pharmacotherapy. Although both elements are proven to reinforce abstinence they are currently unavailable in Albania. Although pharmacotherapies were available in Albania in the past, the uptake was low among smokers, so the pharmaceutical companies have withdrawn them from the market. This could be due to the fact that patients were not aware of pharmacotherapy as a choice because they were not reimbursed, and/or because healthcare professionals were not familiar with pharmacotherapies and hence did not provide relevant advice to smokers to use them. This is critical, as tobacco treatment delivery could help increase the number of smokers who quit and maintain abstinence, thus promoting population health. Even if not subsidised by the government and/ or social insurance companies, cessation medication should be available for sale to the population in need ${ }^{8}$.

Considering all the above, we are calling for several urgent actions by the Albanian authorities to implement WHO FCTC Article 14. These include a situation analysis within Albania, development of national guidelines on tobacco treatment, capacity building for tobacco treatment delivery, pharmacotherapy availability, public opinion awareness and promotion of smoking cessation practices, mass media campaigns implementation, establishment and monitoring of quitlines. Additionally, training of healthcare professionals in evidence-based practices that will influence their knowledge, beliefs, attitudes, perceived behavioural control and intention in introducing tobacco treatment into their daily clinical practice by delivering brief, low-cost tobacco treatment is of paramount importance.

Reforming the current educational curricula for healthcare students, in order to include training for tobacco treatment delivery should also be prioritised by the institutional authorities of the country. It is of paramount importance to implement tobacco dependence treatment measures synergistically with other tobacco control measures. In order to provide coordinated, integrated, holistic, patient-centred and compassionate services, the promotion of tobacco cessation and its treatment are vital issues. The welfare state improvement by supporting tobacco users, implementing tobacco policies and treating their dependence will increase social support and acceptability. Implementing cessation and treatment measures in conjunction with populationlevel interventions covered by other articles of the WHO FCTC, will have a synergistic effect and thus maximise their impact.

\section{CONCLUSION}

Taking into account that smoking is a significantant predictor of poor self-perceived health status in Albania $^{17}$, enforcing tobacco dependence treatment measures can act synergistically with other tobacco control measures maximising their potential success through increases in social support and acceptability. Participation of the public and civic society is of paramount significance to the enforcement of WHO FCTC Article 14. Albania is a country in transition with various financial and budgetary limitations. Therefore, enforcement of cost-effective and evidence-based strategies is essential. 


\section{REFERENCES}

1. World Health Organization. WHO report on the global tobacco epidemic, 2015 : raising taxes on tobacco. 2015. http://apps. who.int/iris/bitstream/10665/178574/1/9789240694606_ eng.pdf?ua=1\&ua=1. Accessed 14 October, 2018.

2. West R. Stop smoking services: increased chances of quitting. 2012. http://www.ncsct.co.uk/usr/pub/Briefing 8.pdf. Accessed 15 October, 2018.

3. World Health Organization. WHO report on the global tobacco epidemic Albania WHO Framework Convention on Tobacco Control (WHO FCTC) status. 2017. http:// apps.who.int/tobacco/surveillance/policy/country_ profile/alb.pdf?ua=1 Accessed 22 May, 2018.

4. Zaloshnja E, Ross H, Levy DT. The impact of tobacco control policies in Albania. Tob Control. 2010;19(6):463468. doi:10.1136/tc.2009.034652

5. Ross H, Zaloshnja E, Levy DT, Tole D. Results from the Albanian Adult Tobacco Survey. Cent Eur J Public Health. 2008;16(4):182-188. doi:10.21101/cejph.a3487

6. Omole OB, Ngobale KN, Ayo-Yusuf OA. Missed opportunities for tobacco use screening and brief cessation advice in South African primary health care: a cross-sectional study. BMC Fam Pract. 2010;11(1):94. doi:10.1186/1471-2296-11-94

7. Stead LF, Buitrago D, Preciado N, Sanchez G, HartmannBoyce J, Lancaster T. Physician advice for smoking cessation. Cochrane Database Syst Rev. 2013;(5):CD000165. doi: 10.1002/14651858.CD000165.pub4

8. World Health Organization. A policy package to reverse the tobacco epidemic http://www.who.int/tobacco/ mpower/mpower_english.pdf. Accessed 14 October, 2018.

9. Masic I, Hadziahmetovic M, Donev D, et al. Public health aspects of the family medicine concepts in South eastern europe. Materia socio-medica. 2014;26(4):277. doi:10.5455/msm.2014.26.277-286

10. Fiore M, Jaén C, Baker T, Bailey W, Benowitz N, Curry $\mathrm{S}$, et al. Treating Tobacco Use and Dependence: 2008 Update, 2008. https://www.aafp.org/dam/AAFP/ documents/patient_care/clinical_recommendations/ TreatingTobaccoUseandDependence-2008Update.pdf. Accessed 14 October, 2018.

11. Cahill K, Stevens S, Perera R, Lancaster T. Pharmacological interventions for smoking cessation: an overview and network meta-analysis. Cochrane Database Syst Rev. 2013;(5):CD009329. doi:10.1002/14651858

12. Cancer Institute N, Department of Health U, Services H, Health Organization W. Monograph 21. The Economics of Tobacco and Tobacco Control. https://cancercontrol. cancer.gov/brp/tcrb/monographs/21/docs/m21_ complete.pdf. Accessed 19 June, 2018.

13. U.S. Department of Health and Human Services. The Health Consequences of Smoking-50 Years of Progress: A Report of the Surgeon General. https:// www.surgeongeneral.gov/library/reports/50-years-of- progress/. Accessed 19 June, 2018.

14. Franco OH, der Kinderen AJ, De Laet C, Peeters A, Bonneux L. Primary prevention of cardiovascular disease: Cost-effectiveness comparison. Int J Technol Assess Health Care. 2007;23(1):71-79. doi:10.1017/s0266462307051598

15. Akanbi MO, Carroll AJ, Achenbach C, et al. The efficacy of smoking cessation interventions in low- and middleincome countries: A systematic review and metaanalysis. Addiction. 2018. doi:10.1111/add.14518

16. West R, Coyle K, Owen L, Coyle D, Pokhrel S; EQUIPT Study Group. Estimates of effectiveness and reach for 'return on investment' modelling of smoking cessationinterventions using data from England. Addiction. 2018;113(Suppl 1):19-31. doi: 10.1111/add.14006

17. Kraja F, Kraja B, Cakerri L, Burazeri G. Sociodemographic and lifestyle correlates of self-perceived health status in a population-based sample of albanian adult men and women. Mater Sociomed. 2016;28(3):173177. doi:10.5455/msm.2016.28.173-177
CONFLICTS OF INTEREST Authors have completed and submitted the ICMJE Form for Disclosure of Potential Conflicts of Interest and none was reported.

FUNDING

There was no source of funding for this research.

PROVENANCE AND PEER REVIEW

Not commissioned; externally peer reviewed. 